\title{
Calcined sugar scum as a low-cost adsorbent for dye removal from aqueous solution: equilibrium, kinetic and modeling
}

\author{
El maguana Y.*, Elhadiri N., Benchanaa M. and Chikri R. \\ Semlalia, Cadi Ayyad University, B.P. 2390, Marrakech, Morocco \\ Received: 21/11/2020, Accepted: 13/09/2021, Available online: 27/10/2021 \\ *to whom all correspondence should be addressed: e-mail: youssefelmaguana@gmail.com \\ https://doi.org/10.30955/gnj.003463
}

Research Laboratory on Materials Reactivity and Process Optimization "REMATOP", Department of Chemistry, Faculty of Science

\section{Graphical abstract}

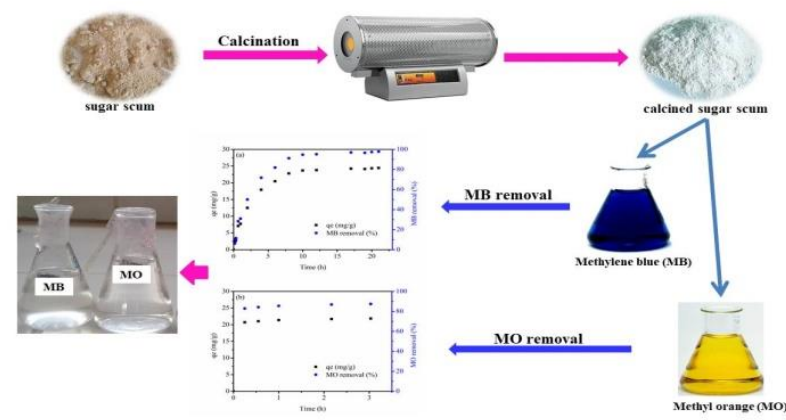

\section{Abstract}

Sugar-refining process in sugar industry produces a high amount of waste that can be used as secondary source material. This waste was calcined and used as low-cost adsorbent for the removal of methylene blue (MB) and methyl orange ( $\mathrm{MO}$ ) as models for cationic and anionic dyes. The kinetic and equilibrium adsorption have been investigated to determine the adsorption mechanisms and the adsorption capacities. The pseudo-first order, the pseudo-second order and the intraparticle diffusion models were used to examine the adsorption kinetic. Adsorption isotherm was modeled using Langmuir and Freundlich models. MB adsorption process can be best described by the pseudo-first order and Langmuir isotherm models while MO adsorption process was best fitted to the Langmuir isotherm with a monolayer maximum adsorption capacity of $40.28 \mathrm{mg} / \mathrm{g}$. Moreover, both pseudo-first order and pseudo-second order models were appropriate to describe the adsorption process of $\mathrm{MO}$. The percentage removal of the calcined sugar scum powder (CSSP) was found greater than $98 \%$ and $87 \%$ for $\mathrm{MB}$ and $\mathrm{MO}$, respectively. The results showed that (CSSP) is a powerful adsorbent for the removal of cationic and anionic dyes.

Keywords: Calcined sugar scum, adsorption kinetic, adsorption isotherm, dye.

\section{Introduction}

The increase of population growth, along with improving economic growth, has brought serious problems including the continuous increase in the amount of industrial solid wastes. These wastes can contain hazardous components that pollute and endanger the environment and cause harmful effects on human and animal health, but they can be used as secondary raw materials. Thus, the scientific community has become increasingly interested in the waste management which can be valorized and used for various applications because they are abundant and renewable. The utilization of industrial solid wastes as raw materials has a positive impact in environment protection by reducing solid wastes and also producing of low-cost materials with high added value. Consequently, the industrial solid wastes have been used in various domains such as manufacturing of adsorbents, production of energy fuels through fermentation processes, production of thermal energy by combustion, preparation of composts, etc (Cerda et al., 2018; Du et al., 2018; El maguana et al., 2018, 2019; Gautam et al., 2014; Marcelo et al., 2017; Omo-Okoro et al., 2018). The utilization of industrial wastes as raw materials for the production of adsorbents has a positive impact in the protection of the environment by reducing industrial solid wastes and minimizing the cost of wastewater treatment (Athalathil et al., 2014; Ennaciri et al., 2014). Various industrial solid wastes have been used as precursors for the preparation of efficient and inexpensive adsorbents such as fly ash and red mud (Wang et al., 2005), wood sawdust (Foo and Hameed, 2012), olive stones and sugar cane bagasse (Moubarik and Grimi, 2015), marble dust (Haddad et al., 2015), Shrimp Shell (Singh et al., 2018), etc.

Adsorption has been found a very efficient technique for wastewater depollution in terms of its capacity to remove a broad range of pollutants, fast adsorption kinetics, simplicity of design, and low cost. Among these pollutants, the dyes used in several sectors such as textiles, cosmetics, plastics, pigments units, leather, and paper industries. They have been considered as the primary pollutant due to their stability and low biodegradability, and therefore cause the degradation of the ecosystem and harmful effects on human and animal health (Elgarahy et al., 2019). So, the removal of dyes from wastewater becomes environmentally important because 
even in low concentration of dye in water can be toxic and highly visible. Therefore, the scientific community has contributed to the treatment of industrial effluents by developing effective dyes removal techniques. The effectiveness of the adsorption for the removal of a wide variety of dyes from wastewater has made it an ideal alternative to other expensive treatment techniques (Crini, 2006; Salleh et al., 2011).

Among solid wastes that could be valorized, the sugar scum powder resulting from the sugar-refining process through juice carbonatation. This waste is separated from the sugary juices using filtration and contains primarily precipitated calcium carbonate as well as minerals and organic materials removed in juice purification (EI maguana et al., 2020). It is disposed of in open fields or sold as compost to farmers to neutralize acidic soils and improve their structures. In our previous study (EI maguana et al., 2018), we used the sugar scum powder for the preparation of an appropriate adsorbent for the methylene blue removal by optimizing the calcination temperature and time. In the present study, the adsorption properties of the calcined sugar scum powder for methylene blue and methyl orange as models for cationic and anionic dyes have been studied. Furthermore, the kinetic and equilibrium adsorption have been investigated to determine the adsorption mechanisms and the adsorption capacities.

\section{Materials and methods}

\subsection{Materials}

The calcined conditions of the sugar scum powder used in this study were described previously in our paper (EI maguana et al., 2018) (calcination temperature $986^{\circ} \mathrm{C}$, calcination time61 $\mathrm{min}$, and in air). CSSP was sieved to obtain particles size less than $200 \mu \mathrm{m}$. MB and MO used as adsorbates in the present study and without further purification were supplied by Merck. A stock solution was prepared by dissolving the weighted quantity of each dye in distilled water, and then solutions of desired concentrations were prepared by diluting stock solution with distilled water.

The structure of methylene blue is given by:<smiles>CN(C)c1ccc2nc3ccc(=[N+](C)[O-])cc-3sc2c1</smiles>

The structure of methyl orange is given by:

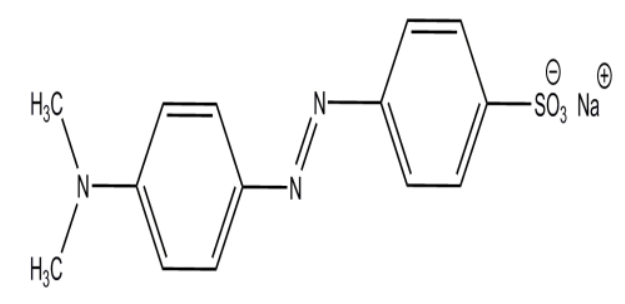

\subsection{Adsorption experiments}

Batch adsorption experiments have been conducted to evaluate the efficiency of CSSP to remove $M B$ and $M O$ dyes from aqueous solution. The experiments were performed in flasks containing a defined amount of CSSP and $100 \mathrm{~cm}^{3}$ of desired concentration of dye solution. The suspensions were mixed on a shaker at $180 \mathrm{rpm}$ during a given time and separated with centrifuge. After adsorption, the residual concentration of $\mathrm{MB}$ or $\mathrm{MO}$ was determined by spectrophotometric method (UV-3100PC Spectrophotometer) at $664 \mathrm{~nm}$ and $462 \mathrm{~nm}$, respectively.

The amount of adsorption at equilibrium $\left(q_{e}\right)$ was defined as the amount of adsorbate per gram of adsorbent (in $\mathrm{mg} / \mathrm{g}$ ) and was calculated using the following equation:

$$
\mathrm{q}_{\mathrm{e}}=\frac{\mathrm{C}_{0}-\mathrm{C}_{\mathrm{e}}}{\mathrm{m}} \times \mathrm{V}
$$

The percentage removal ( $R \%$ ) at equilibrium was calculated using the following relationship:

$$
\mathrm{R} \%=\frac{\mathrm{C}_{0}-\mathrm{C}_{\mathrm{e}}}{\mathrm{C}_{0}} \times 100
$$

Where $C_{0}$ and $C_{e}$ (in $\mathrm{mg} / \mathrm{L}$ ) are the initial and equilibrium concentrations in aqueous solution respectively, $\mathrm{V}(\mathrm{L})$ is the volume of the solution and $\mathrm{m}(\mathrm{g})$ is the mass of the adsorbent.

\subsection{Characterization techniques}

CSSP was characterized by using X-ray powder diffraction (XRD) and scanning electron microscopy coupled with energy dispersive $X$-ray spectroscopy (SEM/EDX) to identify the various phases present in this material and also to examine the morphology and the development of porosity of CSSP as well as to determine its elemental composition (El maguana et al., 2020).

\section{Results and discussion}

\subsection{Characterization of sugar scum}

The XRD pattern, presented in Figure 1, shows the presence of calcium oxide $(\mathrm{CaO})$, calcium hydroxide $\left(\mathrm{Ca}(\mathrm{OH})_{2}\right)$, and Periclase $(\mathrm{MgO})$ phases in CSIW (JCPDS card No. 01-077-2010, 01-084-1265, and 01-079-0612) in CSSP (El maguana et al., 2018). The intense peak appeared at $2 \theta=37.4^{\circ}$ reveals that $\mathrm{CaO}$ is the main phase present in CSSP (Chraibi et al., 2016; Park et al., 2007).

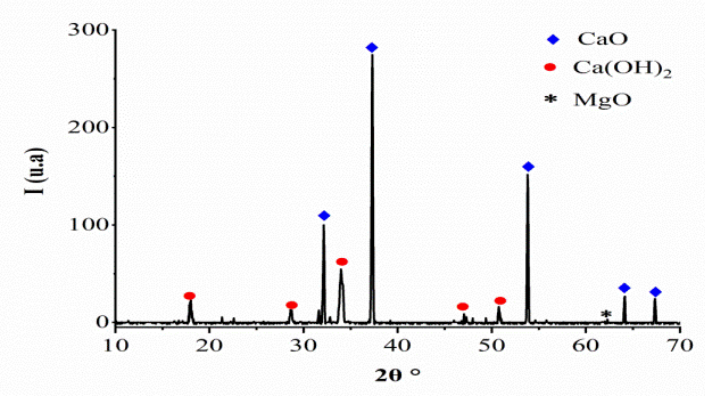

Figure 1. XRD patterns of CSSP.

The SEM micrograph of CSSP (Figure 2) illustrates that this material is formed of agglomeration of small particles with 
irregular shape. Moreover, CSSP exhibits a porous texture due to the release of carbon dioxide. The results of the elemental analysis using EDX (Figure 3 ) indicate that the major elements present in CSSP are calcium (62.55\%) and oxygen (32.87\%). In addition, small amounts of other elements (C, P, Mg, Si, S and Al) are observed for CSSP.

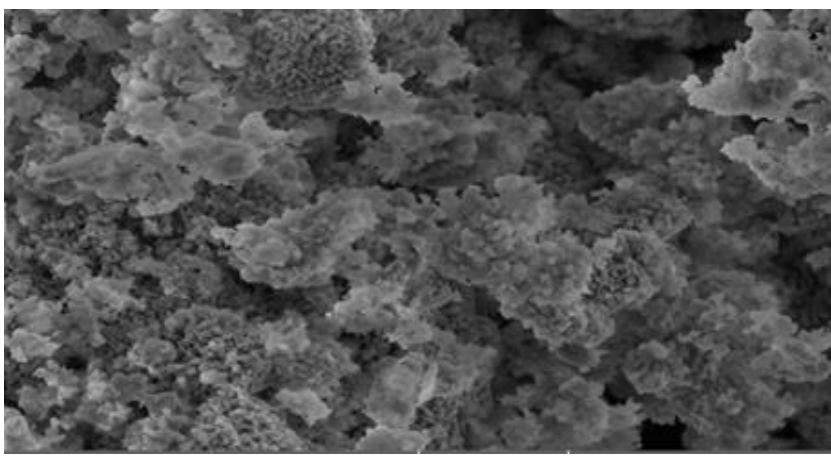

Figure 2. SEM of CSSP.

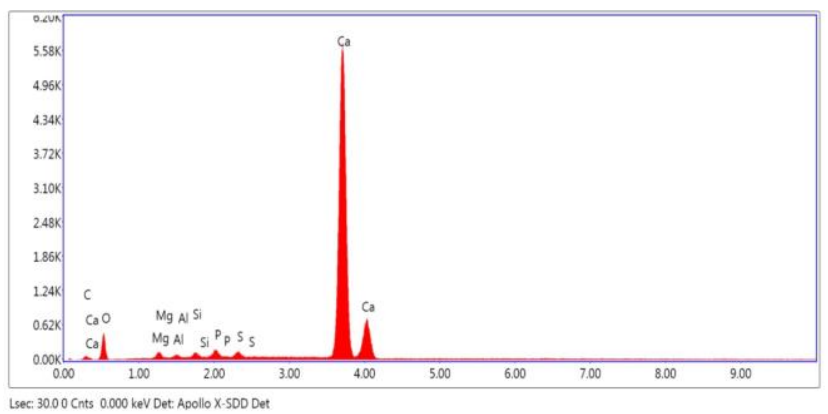

Figure 3. EDX of CSSP.

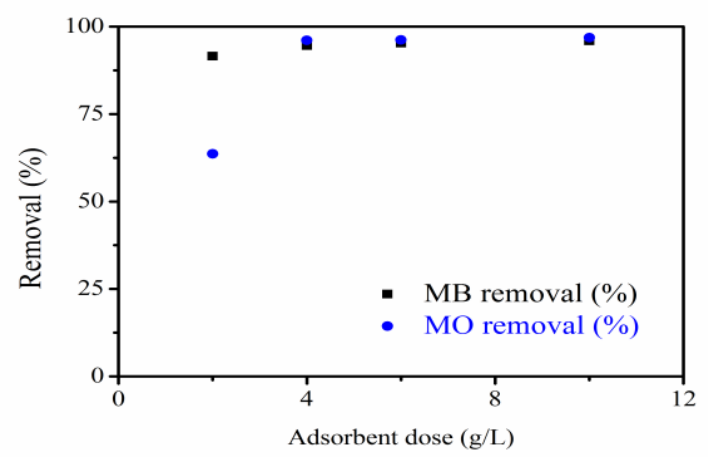

Figure 4. Effect of adsorbent dose on the adsorption of $\mathrm{MB}$ and MO. $\left(\mathrm{t}_{\text {contact }}=24 \mathrm{~h} ;[\mathrm{MB}]_{0}=[\mathrm{MO}]_{0}=100 \mathrm{mg} / \mathrm{L} ; \mathrm{pH}^{\sim} 7 \mathrm{~T}=25^{\circ} \mathrm{C}\right)$.

\subsection{Adsorption studies}

\subsubsection{Effect of adsorbent dose on the adsorption of $M B$ and $\mathrm{MO}$}

Figure 4 shows the effect of the adsorbent dose, ranging from 2 to $10 \mathrm{~g} / \mathrm{L}$, on the adsorption of $\mathrm{MB}$ and $\mathrm{MO}$. The increase of the amount of CSSP in the solution increases the removal percent of dyes until almost $96 \%$. This observation can be explained by the increase in the surface area of the adsorbent and hence the number of available adsorption sites for $\mathrm{MB}$ and $\mathrm{MO}$ adsorption (EI Maguana et al., 2019). The optimal amount of CSSP which corresponds to the maximum of $\mathrm{MB}$ and $\mathrm{MO}$ removal was found to be $4 \mathrm{~g} / \mathrm{L}$. Therefore, adsorbent dose of $4 \mathrm{~g} / \mathrm{L}$ was chosen for dyes removal for further studies.

\subsubsection{Effect of contact time on the adsorption of $M B$ and $\mathrm{MO}$}

The evolution of the percentage removal and the adsorption capacity of CSSP for $M B$ and $M O$ versus contact time are shown in Figures 5 and 6 . The adsorption rate was rapid at the beginning of the process due to the availability of active sites on the exterior surface and after the saturation of those active sites, the dye molecules entered to the pores of the adsorbent with a slower rate to reach the equilibrium time (El Maguana et al., 2019). The equilibrium state was established almost after $10 \mathrm{~h}$ for MB (Figure 5a) and after $1 \mathrm{~h}$ for MO (Figure $5 \mathrm{~b}$ ). Thus, in the subsequent experiments, $10 \mathrm{~h}$ and $1 \mathrm{~h}$ were taken to ensure the adsorption equilibrium of $\mathrm{MB}$ and $\mathrm{MO}$, respectively. In addition, the amounts of $M B$ and $M O$ adsorbed at equilibrium onto CSSP were 24.5 and 21.38 $\mathrm{mg} / \mathrm{g}$, respectively, which correspond to the percentage removal of $98 \%$ and $87 \%$ for $\mathrm{MB}$ and $\mathrm{MO}$. It can be thus noticed that the adsorption process of $\mathrm{MO}$ was higher than that of $\mathrm{MB}$. This can be explained by the size and structure of $\mathrm{MB}$ and $\mathrm{MO}$ molecules. The size of a molecule determines to a certain extent the liquid film diffusion and particle diffusion within the pore network of the adsorbent. When the pore size of the adsorbent corresponds with the size of the adsorbate molecule, the adsorption process will be easier and faster; provided all other factors remain constant. MO has one ring (benzene) on both sides of the azo group $(-\mathrm{N}=\mathrm{N}-)$ giving a total of two rings. Its structure is symmetrical, linear, and more flexible compared to $\mathrm{MB}$ which is formed by three rings (two benzene rings and one heterocyclic) restricting the flexibility of the molecule. MB molecule is more bulky than MO. This above observation and discussion may be the main reason for the difference in the adsorption rates of each dye onto CSSP.

\subsubsection{Adsorption kinetic modeling}

The modeling of the adsorption processes is usually carried out using well-established adsorption kinetic models, which provide invaluable information on the controlling mechanisms of the adsorption process (EI maguana et al., 2020). The overall adsorption process may be controlled either by external or film diffusion, pore diffusion and adsorption on the pore surface, or a combination of more than one step (El maguana et al., 2020). In order to predict the mechanism of the adsorption process of $\mathrm{MB}$ and $\mathrm{MO}$ onto CSSP, the experimental data were fitted by the pseudo-first order (Lagergren, 1898), pseudo-second order (Ho and McKay, 1999), and intraparticle diffusion (Weber and Morris, 1963) models.

The pseudo-first order model is given by the following equation:

$$
q_{t}=q_{e}\left(1-e^{-k_{1} t}\right)
$$

The pseudo-second order model is given as follows:

$$
q_{t}=\frac{k_{2} q_{e}^{2} t}{1+k_{2} q_{e} t}
$$


Where $\mathrm{q}_{\mathrm{e}}(\mathrm{mg} / \mathrm{g})$ is the adsorption amount at equilibrium, $\mathrm{q}_{\mathrm{t}}(\mathrm{mg} / \mathrm{g})$ is the adsorption amount at time $\mathrm{t}(\mathrm{min})$, and $\mathrm{k}_{1}$ $(1 / \mathrm{min})$ and $\mathrm{k}_{2}(\mathrm{~g} / \mathrm{mg} / \mathrm{min})$ are the adsorption rate constants of pseudo-first order and pseudo-second order models, respectively. Kinetic parameters $q_{e}, k_{1}$, and $k_{2}$ can be calculated from the plots of qe versus $t$.
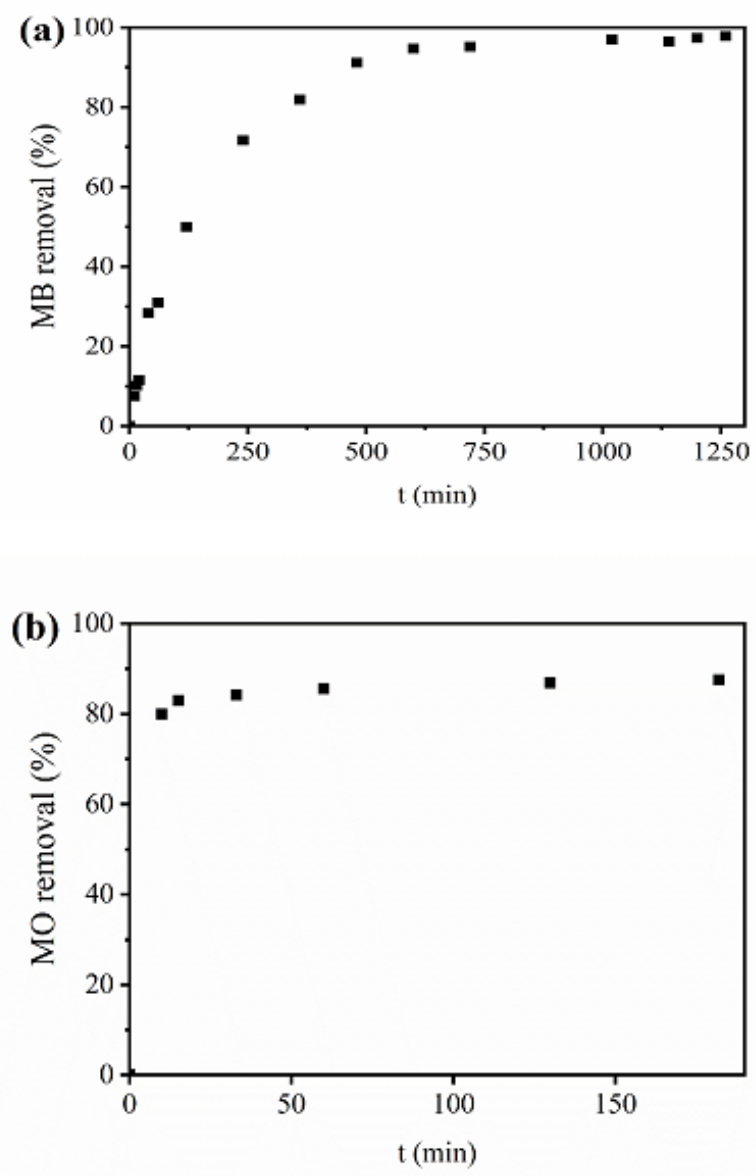

Figure 5. Effect of contact time on (a) $M B$ removal and (b) $M O$ removal. (Adsorbent dose $=4 \mathrm{~g} / \mathrm{L} ;[\mathrm{MB}]_{0}=[\mathrm{MO}]_{0}=100 \mathrm{mg} / \mathrm{L}$; $\mathrm{pH}^{\sim} 7 \mathrm{~T}=25^{\circ} \mathrm{C}$ ).

The plots for pseudo-first order and pseudo-second order kinetic models for $\mathrm{MB}$ and $\mathrm{MO}$ adsorption are presented in Figure $6 a$ and $b$. The calculated parameters of these two kinetics models are presented in Tables 1 and 2 .

Based on the correlation coefficient $\left(R^{2}\right)$ and the adsorption capacity values, it can be deduced the model which describes the adsorption process of $\mathrm{MB}$ and $\mathrm{MO}$ onto CSSP. The results showed that the experimental data of the $M B$ adsorption were efficiently fitted by the pseudo-first order model; higher $\mathrm{R}^{2}$ value and the adsorption capacity calculated by this model $\left(q_{e}\right.$, cal $)$ is closer to the experimental value $\left(q_{e}, \exp \right)$; while both pseudo-first order and pseudo-second order models could be used to describe the adsorption process of $\mathrm{MO}$ onto CSSP because $\mathrm{R}^{2}$ obtained by these two models is greater than 0.99. These results suggest that the boundary layer resistance was the rate-limiting step in the case of $M B$ adsorption process and it was not he rate-limiting step in the case of $\mathrm{MO}$ adsorption process (Barka et al., 2013).
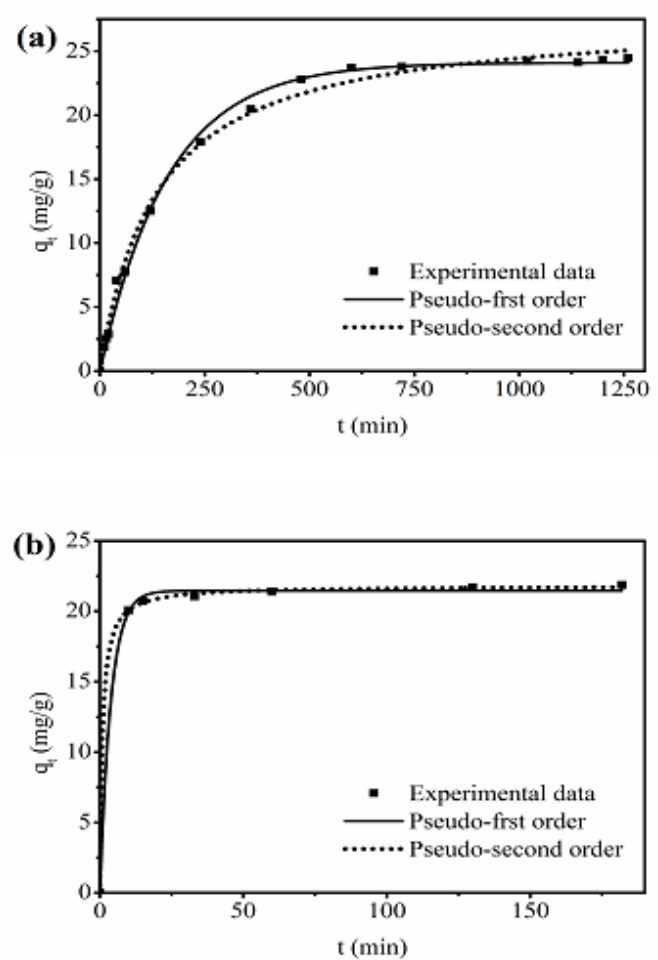

Figure 6. Non-linear fits of pseudo-first order and pseudo-second order models for (a) MB adsorption and (b) MO adsorption $\left([\mathrm{MB}]_{0}=[\mathrm{MO}]_{0}=100 \mathrm{mg} / \mathrm{L} ;\right.$ Adsorbent dose $=4 \mathrm{~g} / \mathrm{L} ; \mathrm{pH}^{\sim} 7 ; \mathrm{T}=$ $\left.25^{\circ} \mathrm{C}\right)$.

The pseudo-first order and pseudo-second order kinetic models could not determine the diffusion mechanism. Hence, the intraparticle diffusion model proposed by Weber-Morris was employed to further evaluate the adsorption of the solute on CSSPand thus to predict the rate limiting steps.

The intraparticle diffusion model is expressed as follows:

$$
q_{t}=k_{i d} t^{1 / 2}+c
$$

Where $q_{t}(\mathrm{mg} / \mathrm{g})$ is the adsorption amount at time $\mathrm{t}(\mathrm{min})$, $\mathrm{k}_{\text {id }}\left(\mathrm{mg} / \mathrm{g} / \mathrm{min}^{1 / 2}\right)$ is the adsorption rate constant of intraparticle diffusion model, and $\mathrm{c}$ is a constant related to the thickness of the boundary layer.

Figure 7 shows the plots of the intraparticle diffusion model of $\mathrm{MB}$ and $\mathrm{MO}$ adsorption. It can be seen that the plots did not pass through the origin, thus the intraparticle diffusion was not the only rate-controlling step of the adsorption process of both dyes, but also other mechanisms may control the rate of adsorption such as the boundary layer diffusion (Foo and Hameed, 2012). The presence of four distinct regions is clearly observed for the transfer of MB to the particles of CSSP (Figure 7a), indicating that the $\mathrm{MB}$ adsorption was influenced by more than one process. The first portion of the plot is attributed to the boundary layer diffusion of MB molecules. Thereafter, the second and third parts were ascribed to the intraparticle diffusion which was the gradual adsorption. In fact, the slope of the linear portion indicates the rate of the adsorption process; the lower slope corresponds to a slower adsorption process 
(Oguntimein, 2015). Thus, the rate of the diffusion of $M B$ molecules through boundary layer film in the initial stage of the adsorption process was slowerthan the rate of the intraparticle diffusion because the slope of the first linear portion was lowerthan of the second and third linear portions. Finally, the last portion is attributed to the final equilibrium stage for which the intraparticle diffusion slows down due to the low concentration dye in the aqueous solution. For $\mathrm{MO}$ adsorption, the plot was Table 1. Kinetic parameters for MB adsorption onto CSSP separated into three steps (Figure 7b). The first step was a rapid diffusion through liquid film to the adorbent exterior surface. The second and third steps were ascribed to the intraparticle diffusion and the final equilibrium stage, respectively. Initially, MO molecules are quickly adsorbed onto the surface of CSIW, and when saturation is reached, $\mathrm{MO}$ molecules are diffused into the interior of adsorbent particles.

\begin{tabular}{|c|c|c|c|c|}
\hline Model & & Parameters & & \\
\hline \multirow{2}{*}{ Pseudo-first order } & $\mathrm{q}_{\mathrm{e}, \mathrm{cal}}(\mathrm{mg} / \mathrm{g})$ & $\mathrm{k}_{1}(1 / \mathrm{min})$ & $\mathrm{R}^{2}$ & $\mathrm{q}_{\mathrm{e}, \exp }(\mathrm{mg} / \mathrm{g})$ \\
\hline & $24.10 \pm 0.26$ & $61.610^{-4} \pm 2.8810^{-4}$ & 0.996 & $24.50 \pm 0.22$ \\
\hline \multirow{2}{*}{ Pseudo-second order } & $\mathrm{q}_{\mathrm{e}, \mathrm{cal}}(\mathrm{mg} / \mathrm{g})$ & $\mathrm{k}_{2}(\mathrm{~g} / \mathrm{mg} / \mathrm{min})$ & $\mathrm{R}^{2}$ & \\
\hline & $27.71 \pm 0.43$ & $2.6810^{-4} \pm 0.2110^{-4}$ & 0.995 & \\
\hline Model & & Parameters & & \\
\hline \multirow{2}{*}{ Pseudo-first order } & $\mathrm{q}_{\mathrm{e}, \text { cal }}(\mathrm{mg} / \mathrm{g})$ & $\mathrm{k}_{1}(1 / \mathrm{min})$ & $\mathrm{R}^{2}$ & $\mathrm{q}_{\mathrm{e}, \exp }(\mathrm{mg} / \mathrm{g})$ \\
\hline & $21.45 \pm 0.15$ & $26.4410^{-2} \pm 2.3010^{-2}$ & 0.998 & $21.38 \pm 1.01$ \\
\hline \multirow{2}{*}{ Pseudo-second order } & $\mathrm{q}_{\mathrm{e}, \mathrm{cal}}(\mathrm{mg} / \mathrm{g})$ & $\mathrm{k}_{2}(\mathrm{~g} / \mathrm{mg} / \mathrm{min})$ & $\mathrm{R}^{2}$ & \\
\hline & $21.81 \pm 0.08$ & $5.2710^{-2} \pm 0.5210^{-2}$ & 0.999 & \\
\hline
\end{tabular}

(a)
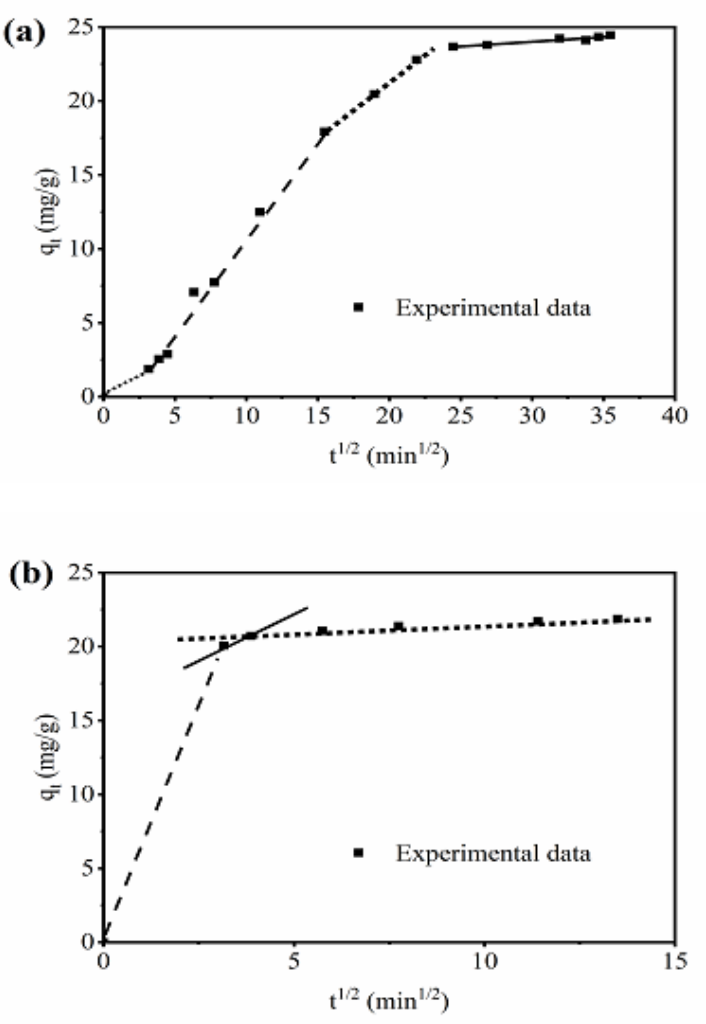

Figure 7. Plot of intraparticle diffusion model for (a) $M B$ adsorption and (b) $\mathrm{MO}$ adsorption $\left([\mathrm{MB}]_{0}=[\mathrm{MO}]_{0}=100 \mathrm{mg} / \mathrm{L}\right.$; Adsorbent dose $\left.=4 \mathrm{~g} / \mathrm{L} ; \mathrm{Ph} 7 ; \mathrm{T}=25^{\circ} \mathrm{C}\right)$.

\subsubsection{Adsorption isotherm modeling}

The adsorption isotherm describes the interaction between the adsorbate molecules and the adsorbent when the system reaches the equilibrium (EI maguana et al., 2020). It provides the qualitative information on the nature of adsorbate-adsorbent surface interactions and could be used to evaluate the adsorption capacity (EI maguana et al., 2020). The experimental data of MB and $\mathrm{MO}$ adsorption isotherms obtained at $20^{\circ} \mathrm{C}$ were fitted to the Langmuir and Freundlich models to find which one can be used to describe the adsorption process of these two dyes onto CSSP. Langmuir equation assumes the monolayer adsorption on a homogenous surface without interaction between adsorbates while the Freundlich isotherm was based on the assumption of the multilayer adsorption on heterogeneous surface (El maguana et al., 2020; El Maguana et al., 2019).

The Langmuir isotherm equation is expressed as:

$$
q_{e}=\frac{q_{m} \cdot K_{L} \cdot C_{e}}{1+K_{L} \cdot C_{e}}
$$

The Freundlich isotherm equation is given as:

$$
\mathrm{q}_{\mathrm{e}}=\mathrm{K}_{\mathrm{F}} \mathrm{C}_{\mathrm{e}}^{1 / \mathrm{n}}
$$

Where $C_{e}(\mathrm{mg} / \mathrm{L})$ is the equilibrium concentration of adsorbate, qe $(\mathrm{mg} / \mathrm{g})$ the amount of adsorption at the equilibrium, $q_{m}(\mathrm{mg} / \mathrm{g})$ is the monolayer adsorption capacity, $\mathrm{n}$ is the Freundlich intensity constant, and $\mathrm{K}_{\mathrm{L}}$ and $\mathrm{K}_{\mathrm{F}}$ are the Langmuir and Freundlich constants, respectively.

The adsorption isotherm of $\mathrm{MB}$ onto CSSP, at temperature $20{ }^{\circ} \mathrm{C}$, is shown in Figure 8a. According to the classification of Giles (Giles et al., 1960), this adsorption isotherm displayed a C-type curve, indicating that the adsorbate molecules penetrate into the solid more readily than those of the solvent Moreover, this curve is characterized by the constant partition of solute between the solution and the adsorbent surface, right up the maximum possible adsorption, where an abrupt change to a horizontal plateau occurs. Figure $8 \mathrm{~b}$ presents the adsorption isotherm of MO onto CSSP, at temperature 
$20{ }^{\circ} \mathrm{C}$. According to the classification of Giles (Giles et al., 1960), it is a L-type curve, suggesting a relatively high affinity between the solid surface and the solute. As more sites in the adsorbent are filled, it becomes increasingly difficult for solute molecules to find a vacant site available.
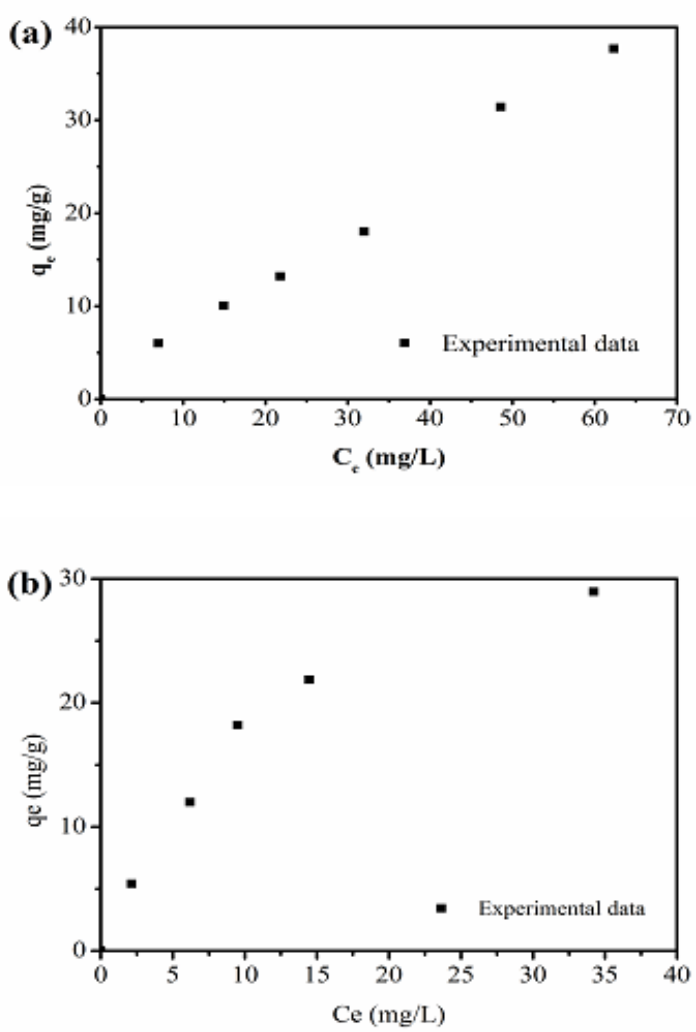

Figure 8. Adsorption isotherm of (a) $\mathrm{MB}$ adsorption and (b) $\mathrm{MO}$ adsorption (Adsorbent dose $=4 \mathrm{~g} / \mathrm{L} ; \mathrm{pH}^{\sim} 7 ; \mathrm{T}=25^{\circ} \mathrm{C} ; \mathrm{t}_{\text {contact }}=10 \mathrm{~h}$ for $\mathrm{MB}$ and $1 \mathrm{~h}$ for $\mathrm{MO}$ ).

Table 3. Langmuir and Freundlich isotherm parameters for $M B$ adsorption onto CSSP

\begin{tabular}{cccc}
\hline Model & \multicolumn{3}{c}{ Parameters } \\
\hline \multirow{2}{*}{ Langmuir } & $\mathrm{q}_{\mathrm{m}}(\mathrm{mg} / \mathrm{g})$ & $\mathrm{K}_{\mathrm{L}}(\mathrm{L} / \mathrm{mg})$ & $\mathrm{R}^{2}$ \\
\cline { 2 - 4 } & $57.34 \pm 3.46$ & $0.016 \pm 0.007$ & 0.96 \\
\hline \multirow{2}{*}{ Freundlich } & $\mathrm{n}$ & $\mathrm{K}_{\mathrm{F}}\left((\mathrm{mg} / \mathrm{g})(\mathrm{L} / \mathrm{mg})^{1 / \mathrm{n}}\right)$ & $\mathrm{R}^{2}$ \\
\cline { 2 - 4 } & $1.17 \pm 0.05$ & $1.04 \pm 0.18$ & 0.98 \\
\hline
\end{tabular}

Table 4. Langmuir and Freundlich isotherm parameters for MO adsorption onto CSSP

\begin{tabular}{cccc}
\hline Model & \multicolumn{3}{c}{ Parameters } \\
\hline \multirow{2}{*}{ Langmuir } & $\mathrm{q}_{\mathrm{m}}(\mathrm{mg} / \mathrm{g})$ & $\mathrm{K}_{\mathrm{L}}(\mathrm{L} / \mathrm{mg})$ & $\mathrm{R}^{2}$ \\
\cline { 2 - 4 } & $40.28 \pm 2.32$ & $7.80 \cdot 10^{-2} \pm 1.00 \cdot 10^{-2}$ & 0.99 \\
\hline \multirow{2}{*}{ Freundlich } & $\mathrm{n}$ & $\mathrm{KF}\left((\mathrm{mg} / \mathrm{g})(\mathrm{L} / \mathrm{mg})^{1 / \mathrm{n}}\right)$ & $\mathrm{R}^{2}$ \\
\cline { 2 - 4 } & $2.04 \pm 0.27$ & $5.3581 \pm 1.06$ & 0.87 \\
\hline
\end{tabular}

Calculated parameters of Langmuir and Freundlich isotherms along with $R^{2}$ values are listed in Table 3 and Table 4. The values of correlation coefficients showed that the isotherm equilibrium data of $\mathrm{MB}$ adsorption were well fitted to the Freundlich isotherm $\left(R^{2}=0.98\right)$ while the isotherm equilibrium data of $\mathrm{MO}$ adsorption were best fitted to the Langmuir isotherm with high regression coefficient $\left(R^{2}=0.99\right)$. These results show that the mechanisms involved in adsorption of $\mathrm{MB}$ and $\mathrm{MO}$ onto CSSP are different, depending on the nature of dye molecules. The adsorption process of MB occurred over a multilayer adsorption on the surface of CSSP with a different energy distribution. Furthermore, the value of $1 / n$ was found between 0 and 1 , which indicates a favorable adsorption of MB onto CSSP. The results also demonstrated that the adsorption process of $\mathrm{MO}$ occurred over a monolayer adsorption on the surface of CSSP without interaction between adsorbates. The maximum monolayer capacity for the $\mathrm{MO}$ adsorption onto CSSPwas found to be $40.28 \mathrm{mg} / \mathrm{g}$ at $20^{\circ} \mathrm{C}$.

\section{Conclusion}

Kinetic and equilibrium studies were conducted for the adsorption of cationic and anionic dyes from aqueous solutions onto CSSP to study the adsorption properties. The results showed that the sugar scum powder is a suitable precursor for the production of adequate adsorbent for dyes removal from industrial effluents. The adsorption isotherms of $\mathrm{MB}$ and $\mathrm{MO}$ fitted well to the Freundlich and Langmuir models, respectively. The adsorption processes of $\mathrm{MB}$ can be described by the pseudo-first order kinetic model. Both pseudo-first order and pseudo-second order models could be used to describe the adsorption process of MO. The percentage removal of CSSP, at $\mathrm{pH}^{\sim} 7$ for an adsorbent dose of $4 \mathrm{~g} / \mathrm{L}$ and an initial dye concentration of $100 \mathrm{mg} / \mathrm{L}$ at $25^{\circ} \mathrm{C}$, was found greater than $98 \%$ and $87 \%$ for $\mathrm{MB}$ and $\mathrm{MO}$, respectively. The above results show that the obtained adsorbent is effective for removing dyes from aqueous solution.

\section{Acknowledgment}

The authors are grateful to the Center of Analyses and Characterization (CAC) of University Caddy Ayyad, Morocco. Also, our respectful thanks go to professors of REMATOP laboratory in Marrakech, Morocco.

\section{References}

Athalathil S., Stüber F., Bengoa C., Font J., Fortuny A. and Fabregat A. (2014). Characterization and performance of carbonaceous materials obtained from exhausted sludges for the anaerobic biodecolorization of the azo dye Acid Orange II. Journal of Hazardous Materials, 267, 21-30. https://doi.org/10.1016/j.jhazmat.2013.12.031.

Barka N., Ouzaouit K., Abdennouri M. and Makhfouk M. El. (2013). Dried prickly pear cactus (Opuntia ficus indica) cladodes as a low-cost and eco-friendly biosorbent for dyes removal from aqueous solutions. Journal of the Taiwan Institute of Chemical Engineers, 44(1), 52-60. https://doi.org/10.1016/j.jtice.2012.09.007.

Cerda A., Artola A., Font X., Barrena R., Gea T. and Sánchez A. (2018). Composting of food wastes: Status and challenges. Bioresource Technology, 248, 57-67. https://doi.org/ 10.1016/j.biortech.2017.06.133.

Chraibi S., Moussout H., Boukhlifi F., Ahlafi H. and Alami M. (2016). Utilization of calcined eggshell waste as an adsorbent for the removal of phenol from aqueous solution. Journal of Encapsulation and Adsorption Sciences, 6(4), 132-146. https://doi.org/10.4236/jeas.2016.64010. 
Crini G. (2006). Non-conventional low-cost adsorbents for dye removal: A review. Bioresource Technology, 97(9), 1061-1085. https://doi.org/10.1016/j.biortech.2005.05.001.

Du C., Abdullah J.J., Greetham D., Fu D., Yu M., Ren L., Li S. and Lu D. (2018). Valorization of food waste into biofertiliser and its field application. Journal of Cleaner Production, 187, 273-284. https://doi.org/10.1016/j.jclepro.2018.03.211.

El maguana Y., Elhadiri N., Benchanaa M. and Chikri R. (2020). Adsorption thermodynamic and kinetic studies of methyl orange onto sugar scum powder as a low-cost inorganic adsorbent. Journal of Chemistry, 2020, 1-10. https://doi.org/ 10.1155/2020/9165874.

El maguana Y., Elhadiri N., Bouchdoug M. and Benchanaa M. (2019). Valorization of powdered marble as an adsorbent for removal of methylene blue using response surface methodology, Applied Journal of Environmental Engineering Science, 1, 53-65.

El maguana Y., Elhadiri N., Bouchdoug M. and Benchanaa M. (2018). Study of the influence of some factors on the preparation of activated carbon from walnut cake using the fractional factorial design. Journal of Environmental Chemical Engineering, 6(1), 1093-1099. https://doi.org/10.1016/ j.jece.2018.01.023.

El maguana Y., Elhadiri N., Bouchdoug M., Benchanaa M. and Boussetta A. (2018). Optimization of preparation conditions of novel adsorbent from sugar scum using response surface methodology for removal of methylene blue. Journal of Chemistry, 2018, 1-10. https://doi.org/10.1155/2018/ 2093654.

El maguana Y., Elhadiri N., Bouchdoug M., Benchanaa M. and Jaouad A. (2019). Activated carbon from prickly pear seed cake: Optimization of preparation conditions using experimental design and its application in dye removal. International Journal of Chemical Engineering, 2019, 1-12. https://doi.org/10.1155/2019/8621951.

Elgarahy A.M., Elwakeel K.Z., Elshoubaky G.A. and Mohammad S.H. (2019). Untapped sepia shell-based composite for the sorption of cationic and anionic dyes. Water, Air, \& Soil Pollution, 230, 217.

Elmaguana Y., Elhadiri N., Bouchdoug M., Benchanaa M. and Jaouad A. (2018). Optimization of preparation conditions of activated carbon from walnut cake using response surface methodology. Moroccan Journal of Chemistry, 6(1), 92-105.

Ennaciri K., Baçaoui A., Sergent M., and Yaacoubi A. (2014). Application of fractional factorial and Doehlert designs for optimizing the preparation of activated carbons from Argan shells. Chemometrics and Intelligent Laboratory Systems, 139, 48-57. https://doi.org/10.1016/j.chemolab.2014.09. 006.

Foo K.Y. and Hameed B.H. (2012). Mesoporous activated carbon from wood sawdust by $\mathrm{K}_{2} \mathrm{CO}_{3}$ activation using microwave heating. Bioresource Technology, 111, 425-432. https://doi. org/10.1016/j.biortech.2012.01.141.

Gautam R.K., Mudhoo A., Lofrano G. and Chattopadhyaya M.C. (2014). Biomass-derived biosorbents for metal ions sequestration: Adsorbent modification and activation methods and adsorbent regeneration. Journal of Environmental Chemical Engineering, 2(1), 239-259. https://doi.org/ 10.1016/j.jece.2013.12.019.
Giles C.H., Macewan T.H., Nakhwa S.N. and Smit D. (1960). Studies in adsorption. A System of classification of solution adsorption isotherms, and its use in diagnosis of adsorption mechanisms and in measurement of specific surface areas of solids. Journal of the Chemical Society, 3973-3993. https://doi.org/10.1039/JR9600003973.

Haddad K., Jellali S., Jaouadi S., Benltifa M., Mlayah A. and Hamzaoui A.H. (2015). Raw and treated marble wastes reuse as low cost materials for phosphorus removal from aqueous solutions: Efficiencies and mechanisms. Comptes Rendus Chimie, 18(1), 75-87. https://doi.org/10.1016/j.crci.2014. 07.006

Ho Y.S. and McKay G. (1999). Pseudo-second order model for sorption processes. Process Biochemistry, 34, 451-465. https://pubs.acs.org/doi/10.1021/acs.oprd.7b00090.

Lagergren S. (1898). Zur theorie der sogenannten adsorption gelöster stoffe. Kungliga Svenska Vetenskapsakademiens, Handlingar, 24(4), 1-39.

Marcelo D., Bizzo W., Alamo M. and Vásquez E. (2017). Assessment of sugarcane byproducts for energy use in Peru. Energy Procedia, 115, 397-408. https://doi.org/10.1016/ j.egypro.2017.05.037.

MoubarikA. and Grimi N. (2015). Valorization of olive stone and sugar cane bagasse by-products as biosorbents for the removal of cadmium from aqueous solution. Food Research International, 73, 169-175. https://doi.org/10.1016/ j.foodres.2014.07.050.

Oguntimein G.B. (2015). Biosorption of dye from textile wastewater effluent onto alkali treated dried sunflower seed hull and design of a batch adsorber. Journal of Environmental Chemical Engineering, 3(4), 2647-2661. https://doi.org/10.1016/j.jece.2015.09.028.

Omo-Okoro P.N., Daso A.P. and Okonkwo J.O. (2018). A review of the application of agricultural wastes as precursor materials for the adsorption of per- and polyfluoroalkyl substances: A focus on current approaches and methodologies. Environmental Technology \& Innovation, 9, 100-114. https://doi.org/10.1016/j.eti.2017.11.005.

Park H.J., Jeong S.W., Yang J.K., Kim B.G. and Lee S.M. (2007). Removal of heavy metals using waste eggshell. Journal of Environmental Sciences, 19(12), 1436-1441. https://doi. org/10.1016/S1001-0742(07)60234-4

Salleh M.A.M., Mahmoud D.K., Karim W.A.W.A. and Idris A. (2011). Cationic and anionic dye adsorption by agricultural solid wastes: a comprehensive review. Desalination, 280(1-3), 1-13. https://doi.org/10.1016/j.desal.2011.07. 019.

Singh N.B., Nagpal G., Agrawal S. and Rachna. (2018). Water purification by using adsorbents: A review. Environmental Technology \& Innovation, 11, 187-240. https://doi.org/ 10.1016/j.eti.2018.05.006.

Wang S., Boyjoo Y., Choueib A. and Zhu Z.H. (2005). Removal of dyes from aqueous solution using fly ash and red mud. Water Research, 39(1), 129-138. https://doi.org/10.1016/ j.watres.2004.09.011.

Weber J.W. and Morris J.C. (1963). Kinetics of adsorption on carbon from solution. Journal of the Sanitary Engineering Division, 89(2), 31-60. 